\title{
Suicídio Assistido em Portugal: a transcendência do direito à saúde com base no princípio da morte digna e na autonomia individual ${ }^{*}$
}

\author{
Assisted Suicide in Portugal: the transcendence of the \\ right to health based on the principle of dignified \\ death and individual autonomy
}

\author{
Ana Paula Zappellini Sassi ${ }^{1}$
}

DOI: http://dx.doi.org/10.11606/issn.2317-2770.v25i2p34-46

\begin{abstract}
Sassi APZ. Suicídio Assistido em Portugal: a transcendência do direito à saúde com base no princípio da morte digna e na autonomia individual. Saúde, Ética \& Justiça. 2020;25(2):34-46.

RESUMO: O suicídio assistido constitui espécie de eutanásia lato sensu, em que uma pessoa dá auxílio a outra para suicidar-se. O procedimento não tem como objetivo central trazer a morte, mas sim poupar o indivíduo de dores que ele considera desnecessárias, tendo em vista que na condição médica em que se encontra, o fim de vida é iminente. A percepção do suicídio assistido como meio para um fim de vida dignificado parte da união dos direitos à vida e à saúde, da autonomia do indivíduo e do princípio da dignidade humana. Objetivou-se, na presente pesquisa, além de defender a prática do procedimento com base na morte digna, expor as controvérsias bioéticas que envolvem o tema e apresentar um quadro da atual situação do auxílio ao suicídio em território português. Para isso, inicialmente foram utilizadas doutrinas de Direito Penal, Constitucional e de Medicina Legal, além de websites jurídicos. A posteriori, numa investigação mais pormenorizada, foram usados livros e artigos científicos com temas correlacionados, além de pesquisas documentais em direito comparado, através das quais pôde-se notar que países como Holanda, Suíça e Bélgica permitem o procedimento, desde que seguidos os requisitos especificados na legislação. Como resultado, chegou-se à conclusão de que o caminho para a disponibilização do suicídio assistido já foi traçado por vários Estados, tomando-se por base o fato de que a morte assistida retém sua importância na defesa da autonomia individual, ou seja, no poder de escolha que o ser humano tem da própria vida, e a sua proibição viola não apenas a autonomia, mas também a autodeterminação e a liberdade de expressão, que são implícitas à existência da pessoa humana.
\end{abstract}

DESCRITORES: Medicina Legal; Direito à Saúde; Direito a Morrer; Eutanásia; Suicídio Assistido; Autonomia Pessoal.

\footnotetext{
* Este trabalho serviu de base para a apresentação do resumo "MORTE ASSISTIDA NA CONTEMPORANEIDADE: A TRANSCENDENTALIDADE DO PRINCÍPIO DA MORTE DIGNA E O DIREITO À SAÚDE”, publicado nos anais do III Congresso Internacional de Direitos Humanos de Coimbra. [Acesso em 2020 mai. 12]. Disponível em: $<$ https://152fe8153c89-4d82-ac2d-8d755e680c6d.filesusr.com/ugd/5fla38_da85f0b13cf44b3b81234f4555ab8bad.pdf>.
}

\footnotetext{
1. Faculdade de Direito de Franca.

Endereço para correspondência: Ana Paula Zappellini Sassi. E-mail: anapzapelini@gmail.com
} 


\section{INTRODUÇÃO}

$\mathrm{O}$ suicídio assistido, também denominado morte assistida ou auxílio ao suicídio, nasce da união dos direitos à vida e à saúde, aliados ao princípio da dignidade da vida humana e da morte digna. Sua prática, comum em alguns países do Globo, não atenta contra a vida do indivíduo, como erroneamente se entende. $\mathrm{O}$ auxílio ao suicídio, da maneira como é defendido nesta pesquisa, não tem como objetivo central trazer a morte, mas sim poupar a pessoa de dores que ela considera desnecessárias, uma vez que o fim de sua vida é iminente. O procedimento funda-se no princípio da morte digna, o qual compreende que, uma vez não tendo o indivíduo mais saúde, seus direitos à vida digna e à saúde convolam-se no direito a uma morte com dignidade.

O suicídio assistido retém sua importância na defesa da autonomia individual, ou seja, no poder de escolha do enfermo ante a própria vida, e a sua proibição viola não apenas a autonomia mas também a autodeterminação, a liberdade de expressão e o direito a uma morte digna, implícitos à pessoa humana e decorrentes do princípio da dignidade humana.

A pesquisa foi iniciada por meio da análise geral, via método bibliográfico, de notícias de jornais, como o Público e o Diário de Notícias portugueses, o The Conversation australiano e o La Cotê suíço. Analisaram-se também websites de organizações nacionais e internacionais, como o Portal da Saúde do Sistema Nacional de Saúde (SNS) e a World Health Organization (WHO). Realizou-se, ademais, a análise de documentários, como The Suicide Tourist.

Posteriormente, numa busca mais aprofundada, verificou-se a legislação portuguesa através, principalmente, do Código Penal, da Constituição da República e do Código Civil. Realizou-se por conseguinte um estudo comparado com outras legislações, tais como a da Suíça e da Holanda. Para tal, utilizou-se a pesquisa em artigos científicos quanto às legislações dos institutos da eutanásia e do suicídio assistido ao redor do mundo, além da autonomia da vontade do doente e das diretivas antecipadas de vontade.

Objetivou-se, de maneira principal, demonstrar a relação do direito à saúde e do princípio da morte com dignidade com o suicídio assistido. Além disso, pretendeu-se defender, com base naquele princípio, a prática responsável da ajuda à morte, assentando-a em condições basilares para que o doente não tenha seus direitos feridos. Por fim, procurou-se realizar uma investigação das jurisdições no mundo que legalizaram o processo da morte digna, demonstrando a seriedade dos procedimentos diante do compromisso desses Estados com o bem-estar dos seus cidadãos.

\section{O DIREITO À SAÚDE}

A saúde é um direito humano fundamental e social. Quaisquer violações a esta garantia básica ofendem a dignidade do ser humano, que se encontra sob a tutela dos Estados. Logo, o zelo pela saúde dos indivíduos constitui poder e dever estatal. Na $30^{\mathrm{a}}$ Assembleia Mundial de Saúde, organizada pela Organização Mundial da Saúde (OMS), foi criado o Movimento Saúde para Todos nos Anos 2000, que resultou na elaboração de uma declaração que, conforme Caldas e Santos ${ }^{1}$, "reafirmou o significado de saúde como um direito humano fundamental e como uma das mais importantes metas mundiais para a melhoria social".

Esse documento, nomeado Declaração de Alma-Ata ${ }^{2}$, profere que a saúde, como circunstância de inteiro bem-estar físico, mental e social, e não apenas a inexistência de enfermidade, é um direito fundamental, e que a essencial meta social a ser alcançada é o mais alto nível disponível de saúde. O direito à saúde compreende, consequentemente, não apenas a prevenção e a proteção relativamente a enfermidades, mas também o bem-estar mental e social das pessoas. E, se é responsabilidade dos Estados zelar pela saúde dos indivíduos, é sua obrigação preveni-los de quaisquer tormentos que possam prejudicar seu bem-estar na comunidade como um todo.

\section{O PRINCÍPIO DA MORTE DIGNA}

Conforme Ângela Raimundo 3 , a dignidade da pessoa humana é consagrada pela Constituição da República Portuguesa ${ }^{4}$ e encorpa-se no artigo $25^{\circ}, n^{\circ} 1$, que a reconhece enquanto direito à integridade pessoal. $\mathrm{A}$ dignidade do indivíduo requer que a vontade do paciente, implícita à sua autonomia pessoal, seja respeitada. Logo, reside nela o fundamento para a aceitação da vontade do adoentado de decidir sobre sua vida - e morte. Acrescenta a autora, ainda, que o respeito pela dignidade humana estaria ausente uma vez retirada do doente a possibilidade de optar por um fim de vida sem sofrimento, pois, dessa forma, estaria ele condenado à vida, vítima de uma ilegítima sobrevivência ${ }^{3}$.

Diante da proibição, em vários Estados, de práticas como a eutanásia e o auxílio ao suicídio, que visam ao termo final da vida de pessoas enfermas, surge o questionamento quanto à existência, com base no princípio da dignidade da pessoa humana, da prerrogativa de uma morte digna. De início, entende-se, por morte com dignidade a morte rápida, indolor, que não traz sofrimento. $\mathrm{O}$ princípio da morte digna seria, consequentemente, a faculdade dada ao indivíduo - que, adoentado, entende ter sua dignidade em vida violada a datar do instante em que se percebe em condições de dor e sofrimento em final de vida - de ter sua vida findada de maneira breve e sem dor, a partir do momento em que não 
há mais como seu direito à saúde ser tutelado no sentido de que lhe seja proporcionado bem-estar físico e mental.

Segundo Ferreira Couto ${ }^{5}$, o Tribunal Europeu dos Direitos do Homem (TEDH), nos acórdãos dos casos Pretty v. The United Kingdom, Haas v. Switzerland e Koch v. Germany reconheceu que um dos prismas do direito ao respeito pela vida privada - com base no Art. $8^{\circ}$, da Convenção Europeia dos Direitos dos Homens $(\mathrm{CEDH}),{ }^{6}$ que dispõe sobre o direito ao respeito e à não ingerência de autoridades públicas na vida privada dos indivíduos - é o da prerrogativa de escolha, por parte da pessoa, de quando e de que modo sua vida deve terminar, desde que esteja em condições de formar sua vontade de maneira livre e agir de acordo com ela.

Desse modo, nota-se que o TEDH admite o direito de autodeterminação do enfermo, que sofre insuportavelmente por conta de uma doença séria e sem cura, no sentido de optar por uma morte digna, contanto que essa decisão seja livre e consciente. A Declaração Universal dos Direitos Humanos ${ }^{7}$, adotada pela Organização das Nações Unidas (ONU) em 1948, arrola os direitos humanos básicos a serem respeitados pelos Países do mundo. Profere, em seu artigo $1^{\circ}$, que todos os indivíduos nascem dotados de liberdade e igualdade em dignidade e direitos, e devem agir com fraternidade uns para com os outros. Nesse sentido, questiona-se, diante dessa obrigação fraterna implícita aos indivíduos, se não estaria incluso o dever de acatamento do desejo do adoentado - que se encontra em uma situação desarmônica, passando por dores insuportáveis à espera do fim da vida - de receber ajuda para a morte porque entende que sua dignidade está sendo violada a contar de quando se vê obrigado a continuar a viver sem mais expectativas de vida, passando por grande sofrimento.

José de Faria Costa (apud Couto, 2017, p. 53), nessa linha, defende a admissibilidade do auxílio ao suicídio como uma ação médica de curar para além da cura, "devido ao novo paradigma da autodeterminação do doente presente na relação médico-doente e, consecutivamente, no ato médico". O autor considera que a qualidade de vida é o mais relevante, uma vez que a quantidade, apesar de constituir uma realidade, por conta dos avanços das ciências e da medicina, proporciona que a morte, na perspectiva do enfermo, seja considerada mais um deixar de viver do que um fim propriamente dito. Acrescenta, finalmente, que quando não há esperança de vida e "a qualidade de vida atinge níveis de humilhação", o sofrimento é exorbitante de modo que se vê o deixar de viver como uma opção viável.

O direito à saúde e sua transcendência com base no princípio da morte com dignidade

É notável a dualidade existente entre o dever de proteção à saúde, inerente à ética médica, e o dever de respeito pelas opções do enfermo. Nessa linha, quando não há equilíbrio entre ambos, entende-se que obedecer a posição do doente seja a opção mais sensata, uma vez que, assim, sua dignidade é respeitada, através de um ato considerativo e humano do médico responsável por auxiliá-lo a pôr fim à sua existência ${ }^{8}$.

O direito do ser humano a morrer, pois, transcende, ultrapassa seu direito à saúde a partir do momento em que se constata que sua enfermidade é terminal e, consequentemente, não há mais maneiras de tutelar seu bem-estar em vida para que volte ao status quo anterior - ser saudável novamente. Tal direito não compreende apenas sua intenção de findar a vida, mas também o poder de se expressar, de despedir-se dignamente do mundo e de não mais sofrer em vão.

Os direitos à saúde e à assistência médica, desse modo, estendem-se até o final da vida, em conformidade com as convicções do paciente, ao convolarem-se, com base na autonomia individual, na faculdade do pedido de morte fundado na dignidade humana. Este clamor, baseado na morte digna, não descaracteriza a dignidade de quem, na mesma situação, deseja preservar a vida, afinal, como bem comenta Diana Ferreira Couto ${ }^{5}$, aquele que se acha num processo de morte vivido em hospitais não deixará de ser pessoa somente por ser um indivíduo vulnerável, visto que, se permanece a ser capaz de tomar decisões com liberdade e consciência, segundo sua autodeterminação, diante da notícia de uma morte certa, terá a liberdade de optar ou não pelo fim da vida.

\section{O PEDIDO DE AUXÍLIO AO SUICÍDIO}

O auxílio ao suicídio consiste no pedido de uma pessoa para que um terceiro o ajude a findar sua vida. Levando-se em consideração o princípio da dignidade humana e os direitos à vida e à saúde, defende-se a prática desse procedimento com base no respeito pela autonomia do sujeito e a sua dignidade em fim de vida, uma vez que o indivíduo, sem mais expectativas de sobrevivência a longo prazo, e com a saúde debilitada, tem seus direitos à vida e à saúde transformados na prerrogativa de optar por uma morte que considere digna.

Cumulativamente, reconhece-se a necessidade da existência de alguns requisitos essenciais para que este instituto seja realizado de maneira legal, humana e não arbitrária. Primeiramente, a doença ou a condição deve ser incurável e irreversível, além de gerar grande sofrimento físico e/ou psicológico à pessoa. Além disso, o pedido de ajuda deve partir de quem entende que o necessita. E a pessoa a receber assistência precisa ter capacidade de discernimento e lucidez suficientes para se autodeterminar no momento dessa solicitação.

Nesse âmbito, tendo em vista a situação de vulnerabilidade em que já se encontra o doente abalado psicologicamente por conta da notícia de que 
sua situação médica é incurável e a morte é iminente - é necessário que se constate que ele tem capacidade jurídica para realizar o pedido de assistência ao suicídio. Para tal, é essencial que a lei do respectivo país, relativa à capacidade do agente, seja analisada.

Em Portugal, o Código Civil ${ }^{9}$ prevê, em seu Art. $128^{\circ}$, que os menores não detêm capacidade para o exercício de direitos. Assim, a capacidade civil se adquire, por regra, com a maioridade, aos 18 anos. Pessoas com idade inferior a essa devem ter seus direitos tutelados pelos representantes legais. Ademais, são incapazes, além dos menores de idade, os interditos. Conforme o artigo $138^{\circ}$ do mesmo diploma ${ }^{9}$, sujeitam-se à interdição "aqueles que por anomalia psíquica, surdez-mudez ou cegueira se mostrem incapazes de governar suas pessoas e bens". De acordo com Cunha Rodrigues ${ }^{10}$, a interdição acarreta na "negação de capacidade geral de exercício ao incapaz e na nomeação de um tutor, a quem caberá agir enquanto representante do interdito". Nesse sentido, os interditos, assim como os menores, não detêm capacidade existencial, ou seja, não são considerados capazes para a tomada de decisões relativas à vida e à saúde, ficando essas questões a cargo, no primeiro caso, de um tutor e, no segundo, do representante legal.

Já relativamente à capacidade para administração do patrimônio, são consideradas incapazes as pessoas sujeitas à inabilitação, que devem ser assistidas na realização de alguns atos da vida civil. De acordo com o artigo $152^{\circ}$ da Lei Civil Portuguesa, podem ser inabilitadas aquelas pessoas "cuja anomalia psíquica, surdez-mudez ou cegueira, embora de carácter permanente, não seja de tal modo grave que justifique a sua interdição". Cunha Rodrigues ${ }^{10}$ esclarece que "o efeito principal da inabilitação consiste na designação de um curador, que fica incumbido de assistir o incapaz na prática de actos [sic] de disposição de bens entre vivos".

Outrossim, o inabilitado é considerado incapaz apenas com relação à gestão de seus bens, ou seja, somente no tocante à tomada de decisões patrimoniais, tendo, em tese, capacidade existencial para gerir os atos da vida. Entretanto, mesmo sendo capaz, pode ocorrer que em alguns casos o indivíduo inabilitado não detenha lucidez suficiente para decidir por si em relação à sua vida. Deve o médico responsável pelo acompanhamento do caso, nessa hipótese, atestar que sua declaração de vontade é séria e não deriva de vícios. Um indivíduo que é ébrio habitual, por exemplo, por conta do uso excessivo de bebidas alcoólicas ou substâncias estupefacientes, ainda que sujeito à inabilitação, continua, em tese, capaz de consentir em atos da vida. Porém, por conta dos efeitos dessas substâncias, sua vontade pode estar viciada. Nesse caso, seria necessário aguardar que o vício cessasse para que sua declaração de vontade fosse colhida.

Todavia, Rodrigues ${ }^{10}$ pontua que a legislação portuguesa vem sendo questionada, tendo em vista a necessidade de adaptação do texto legal à realidade atual, em que são defendidos os direitos humanos das pessoas com deficiência como pessoas autônomas. Nessa linha, a Comunidade Internacional compreende que a capacidade civil pode somente ser restringida proporcionalmente à necessidade "para a salvaguarda da pessoa com deficiência e dos seus bens, na medida adequada ao caso concreto e pontualmente dirigida às inaptidões (e ao grau destas) físicas, intelectuais, mentais ou sensoriais verificadas" $"$.

Além do mais, Portugal é um dos países signatários da Convenção Internacional sobre os Direitos das Pessoas com Deficiência ${ }^{11}$ que prevê, em seu art. $12^{\circ}$, que os "estados Partes reconhecerão que as pessoas com deficiência gozam de capacidade legal em igualdade de condições com as demais pessoas em todos os aspectos da vida". Mais que isso, a Carta dos Direitos Fundamentais da União Europeia (CDFUE) promove o reconhecimento "do direito das pessoas com deficiência a se beneficiarem de medidas destinadas a assegurar a sua autonomia e autodeterminação (na gestão dos seus interesses e da sua vida)" ${ }^{10}$, revelando a capacidade patrimonial e existencial das pessoas com deficiência.

Nesse âmbito, o regime brasileiro das incapacidades, por exemplo, diverge do português quanto ao tratamento dado às pessoas com deficiência. Ficou estabelecido, com o advento do Estatuto da Pessoa com Deficiência (Lei $\left.n^{0} 13.146 / 15\right)^{12}$, que a deficiência física ou psíquica não limita as pessoas para o exercício dos atos da vida civil. Consoante esclarecem Pereira e Matos $^{13}$, o antigo regime civil das incapacidades colocava as pessoas com deficiência numa posição de vulnerabilidade, declarava-as incapazes para a realização de atos civis, e transferia o poder de decisão quanto à vida e ao patrimônio às mãos de terceiro, similarmente ao que ocorre em Portugal.

Nesse sentido, a capacidade era subdividida em duas, sendo que "a capacidade de direito seria o atributo de toda pessoa natural ser considerada um sujeito perante o ordenamento jurídico, enquanto a capacidade de exercício se remeteria à aptidão da pessoa exercer seus direitos por si própria" 13 e os incapazes eram detentores apenas da primeira. Assim, de maneira parecida ao ordenamento civil português, o Código Civil brasileiro incluía no rol das incapacidades as pessoas com deficiência. Esses indivíduos, ao serem considerados incapacitados, tinham seus direitos da personalidade restringidos, pois não podiam exercer prerrogativas no sentido de decidir sobre seus bens ou sua vida: "a interdição e declaração de incapacidade absoluta obstavam a liberdade de escolha não somente para atos patrimoniais, mas também para atos existenciais, pois o regime da curatela se pautava em paradigma de substituição da vontade" "13.

Sendo assim, com a criação do Estatuto da Pessoa com Deficiência ${ }^{12}$, que visa à promoção da igualdade 
para exercício de direitos às pessoas com deficiência, o sistema das incapacidades brasileiro tornou-se mais flexível. Flávio Tartuce ${ }^{14}$ pontua que aquelas deixaram de ser consideradas absolutamente incapazes, tornando-se, em regra, plenamente capazes para a tomada de decisões patrimoniais e existenciais. Entretanto, em alguns casos esses indivíduos, assim como quaisquer outras pessoas, podem ser declarados relativamente incapazes para atos da vida civil se ébrios habituais, viciados em substâncias tóxicas, pródigos ou quando, por motivo transitório ou permanente, não puderem exprimir a vontade, parecidamente aos casos de inabilitação para os atos patrimoniais da legislação portuguesa ${ }^{14}$.

Conforme exposto, apesar dos avanços da Comunidade Internacional na promoção da igualdade das pessoas com deficiência, a legislação civil portuguesa ainda entende que esses indivíduos são incapazes quanto aos atos relacionados à sua existência, devendo ser representados por pessoa designada. Entende-se que a vontade do doente deve ser pautada tendo-se como parâmetro a legislação de cada Nação, visto que há divergências a depender do País em que a morte assistida ocorrerá. Assim, há também de se procurar, em cada ordenamento jurídico, a intenção do legislador, para saber se o legalmente responsável pelo incapaz poderá decidir em nome dele, caso este expresse a vontade de receber auxílio para morrer. Vital Silva ${ }^{15}$ explica que na Holanda, por exemplo, a prática da eutanásia stricto sensu - eutanásia propriamente dita, através da qual terceiro retira a vida da pessoa enferma, diferentemente do suicídio assistido, no qual uma pessoa dá auxílio para que o próprio indivíduo se suicide - é legalmente realizada em jovens a partir dos 14 anos, desde que estes sejam representados pelos pais.

Já no âmbito penal, no que toca à incapacidade por menoridade, o legislador português reconheceu explicitamente a autonomia do menor ao prever que os maiores de 16 anos são imputáveis, ou seja, passíveis de responder pelas condutas que tomarem em divergência com o direito. A lei penal dispõe que estes jovens têm capacidade para dar seu consentimento em relação aos atos da vida, ou seja, para tomada de decisões existenciais, e da união dos artigos $38^{\circ}, \mathrm{n}^{\mathrm{o}} 3^{\circ}$, do Código Penal Português ${ }^{16}$ - segundo o qual, o consentimento apenas se faz eficaz se prestado por pessoa maior de 16 anos, que tenha discernimento para tal - e artigo $150^{\circ}$, do mesmo diploma ${ }^{16}$ - que dispõe sobre intervenções e tratamentos médico-cirúrgicos - pode-se inferir que os menores maduros têm capacidade, inclusive, para dar seu consentimento no caso de intervenções médicocirúrgicas ${ }^{17}$.

Nesse sentido, de acordo com André Dias Pereira (apud Coutinho, 2016, p. 28) ${ }^{17}$, essa capacidade do menor para consentir resume-se na "capacidade de tomar uma decisão racional sobre os riscos, sacrifícios dos seus próprios bens jurídicos". Coutinho ${ }^{17}$ explica, entretanto, que apesar de o legislador penal reconhecer a eficácia do consentimento prestado desde os 16 anos - existindo uma presunção legal de capacidade nesse sentido - é necessário balancear se, além da idade, o menor tem discernimento suficiente para compreender os riscos, a natureza e os resultados da intervenção médica, devendo o médico analisar a capacidade diante do caso concreto.

De modo exemplificativo, a adolescente pode, a partir dos 16 anos, concordar com a interrupção voluntária da gravidez, desde que o médico constate que tem ela compreensão suficiente para apreciar o significado e a abrangência desse consentimento. Isto posto, numa interpretação inicial da lei penal, percebe-se que a ajuda ao suicídio poderia, como intervenção médica de curar para além da cura $^{5}$, desde que consagrada por lei específica e aceita pelos costumes, seguir os mesmos parâmetros da interrupção voluntária da gravidez. Logo, o consentimento dado por pessoa maior de 16 anos que tivesse discernimento suficiente para avaliar seu sentido e alcance e de deliberar de acordo com essa valoração, seria penalmente válido para fins de auxílio no término de vida.

Em conclusão, quanto à capacidade do doente para a tomada da decisão quanto ao auxílio ao suicídio, seria necessário analisá-la nas esferas penal e civil. A capacidade civil existencial refere-se à capacidade de decisão do agente quanto a atos da vida, e, neste caso específico, em relação ao procedimento da ajuda ao suicídio. Já a capacidade civil patrimonial compreende atos tocantes ao patrimônio da pessoa. Conforme exposto, em Portugal os interditos são considerados incapazes para a gestão de sua vida, assim como os menores de idade, não detendo capacidade para consentir civilmente quanto à realização do procedimento. Além disso, nos casos em que se vê passível a inabilitação do enfermo - relativa tão somente a atos patrimoniais -, deve-se analisar se a vontade do agente não contém vícios, pois ela deve ser clara e séria. Já a capacidade penal traduzse na imputabilidade que, de acordo com Isabel Luís do Couto $^{18}$, é a "idade da responsabilidade criminal, a partir da qual o indivíduo pode ser penalmente responsabilizado pelos seus actos [sic]". Desse modo, segundo a legislação portuguesa, os menores de 16 anos não são penalmente responsáveis, pois não têm capacidade de entendimento do caráter lícito ou ilícito da ação, sendo que, nos casos de intervenções médicas, podem manifestar consentimento apenas a partir dos 16 anos.

Além da capacidade do agente, tem-se, como requisitos essenciais para a realização do procedimento de maneira não arbitrária, a reiteração e a seriedade do pedido. Vê-se necessário que o auxílio ao suicídio seja requerido diversas vezes, de modo sensato. Jamais se deve acatar o pedido realizado apenas uma vez ou de modo jocoso, tendo em vista a extrema importância do 
bem com o qual se está a lidar: a vida.

Por último, quanto à condição ou enfermidade irreversível e terminal, assinala-se que deve causar grande sofrimento físico e/ou psicológico ao paciente, e o procedimento há de ser necessariamente realizado por um médico. O estado da doença necessita ser comprovado por laudo que constate sua irreversibilidade e terminalidade. De acordo com Gutierrez ${ }^{19}$, a condição terminal ocorre "quando se esgotam as possibilidades de resgate das condições de saúde do paciente e a possibilidade de morte próxima parece inevitável e previsível". O estágio de terminalidade constata-se, portanto, a partir de quando não se vê mais possível tutelar a saúde do indivíduo, e a morte é iminente.

Em suma, defende-se a obrigatoriedade de que a doença ou condição médica seja terminal, pois a violação da dignidade em fim de vida ocorreria a partir do momento em que, não havendo possibilidade de cura e sendo a morte próxima, o indivíduo, passando por muitas dores, não teria a opção de escolher pela sua antecipação, sendo obrigado a suportar sofrimento que considera desnecessário, até o advento da morte natural.

\section{A ajuda ao suicídio como boa morte}

O auxílio ao suicídio é uma espécie de eutanásia lato sensu. A palavra eutanásia, por sua vez, tem origem grega, e advém da união das palavras $e u$ - bem - e thanasia - morte. Em seu significado literal, por conseguinte, trata-se de uma boa morte. Por esse motivo, o procedimento é também conhecido como homicídio piedoso, médico, compassivo, caritativo ou consensual ${ }^{20}$.

Sua realização, desse modo, relacionar-se-ia a algo positivo, uma alternativa à morte dolorosa e ao sofrimento no final da vida. É, pois, o pedido do paciente para que o médico o ajude a ter uma boa morte, isto é, indolor, tranquila, que encerre seu sofrimento. Importante salientar que, diferentemente do que ocorre na eutanásia stricto sensu, em que a vida do paciente é findada pelo médico de forma ativa, na ajuda ao suicídio o realizador do ato é o próprio doente que, mediante auxílio de terceiro, tira a própria vida.

\section{Morte assistida em Portugal}

Em Portugal, o auxílio ao suicídio é crime. Conforme o artigo $135^{\circ}$ do Código Penal, aquele que presta ajuda a alguém que deseja suicidar-se é punido com pena de prisão. Conforme Pinto e Cunha ${ }^{21}$, apesar de Portugal ainda criminalizar o suicídio assistido, vêse importante notar que o país já admite o testamento vital, que dá maior autonomia à pessoa em relação à maneira como deseja terminar a vida, uma vez que esta pode, desde que maior de idade e capaz, manifestar antecipadamente sua vontade - consciente, livre e esclarecida - relativamente aos cuidados de saúde que deseja ou não receber no caso de se encontrar incapaz para expressar seu arbítrio em momento futuro.

Além disso, o País autoriza a prática da ortotanásia, que resume o termo laico do desligamento de aparelhos que sustentam a vida de modo artificial, objetivando, como bem expõe Villas-Bôas ${ }^{22}$, fornecer alívio ao doente "sem interferir no momento da morte, sem encurtar o tempo natural de vida nem adiá-lo indevida e artificialmente, possibilitando que a morte chegue na hora certa, quando o organismo efetivamente alcançou um grau de deterioração incontornável”. Tal procedimento procura findar tratamentos que prolongam a vida, porém se veem inúteis à cura do doente ${ }^{20}$. Em Portugal, portanto, o enfermo tem a autonomia de optar pela não continuação de procedimentos médicos que mantenham sua vida de maneira artificial, através de disposição no testamento vital.

Todavia, a nação portuguesa ainda tem muito a percorrer no sentido de descriminalizar a ajuda ao suicídio. Como bem elucidam Brito, Mata, Neves e Morão ${ }^{23}$, uma maneira de permitir legalmente o auxílio ao suicídio seria excluindo a ilicitude penal do auxílio ativo ao suicídio, "com base no consentimento do ofendido, isto é, daquele cuja autodeterminação relativamente à vida sofreu interferência de terceiro, no que concerne à concretização da decisão de 'deixar de viver'”. Em outras palavras, poder-se-ia deixar de punir a ajuda ao suicídio que ocorresse com base no consentimento explícito do adoentado, uma vez que é direito seu decidir a respeito não somente de sua vida, mas também de sua morte.

Ademais, quanto à indisponibilidade da vida, concluem que "a vida apenas é indisponível relativamente a ataques perpetrados por terceiro" ${ }^{23} \mathrm{e}$, sendo a lesão da vida efetuada pelo doente - seu titular -, o auxílio ao suicídio seria um acréscimo ao perigo de autolesão, por intermédio de terceiro na concretização da decisão do doente de morrer $^{23}$. Ou seja, a ajuda ao suicídio não seria, assim, vista como um atentado do médico à vida do paciente, uma vez que aquele apenas serve como intermediador para que este realize sua vontade de findar a própria vida, ação que não é considerada culpável pelo ordenamento jurídico português, tendo em vista que não se faz presente o dever de continuar a viver.

Dessa maneira, na linha de raciocínio de Brito, Mata, Neves e Morão ${ }^{23}$, segundo o artigo $38^{\circ}$ do Código Penal Português ${ }^{16}$ - que prevê que "o consentimento exclui a ilicitude do facto [sic] quando se referir a interesses jurídicos livremente disponíveis e o facto [sic] não ofender os bons costumes" -, sendo o procedimento consentido pelo paciente, restaria apenas a não ofensa aos bons costumes para que a ajuda ao suicídio deixasse de ser punível.

Nessa linha, partindo-se do pressuposto de que o direito à saúde que o doente detém convola-se na 
faculdade de optar pela morte digna a partir do momento em que este não mais tem chances de recuperação, notase que o procedimento, se praticado com seriedade, não ofende a moral, por consistir num ato de dignidade e fraternidade do médico que acata a súplica do enfermo, que, sem mais chances de ter uma boa vida e, com morte iminente, deseja antecipar o fim de sua vida para não continuar a prolongar suas dores. Tampouco afrontaria os costumes, uma vez que a ortotanásia, instituto que consiste na limitação terapêutica, ou seja, retirada dos aparelhos que sustentam artificialmente a vida ${ }^{22}$, já é aceita pela sociedade portuguesa e, apesar de diferenciarse procedimentalmente do suicídio assistido por não objetivar matar o paciente, tem como finalidade última a mesma: dar a oportunidade de uma morte digna a ele.

Quanto à indisponibilidade da vida, entende-se que uma vez não sendo a tentativa de suicídio punida, já é a vida considerada um bem disponível, pois, caso o sujeito não tivesse o livre arbítrio para dispor dela, a simples tentativa de tirá-la seria penalizada. Mais que isso, conforme ensinamentos de Jorge de Figueiredo $\operatorname{Dias}^{24}$, não se considera suicídio "quando alguém, atingido por doença grave e terminal, desiste de lutar contra o inevitável. Não cometem, por isso, a infracção [sic] os que, neste contexto, asseguram apoio físico ou psíquico ao doente". Conclui que também não constitui crime de auxílio ao suicídio a recusa do tratamento por parte de um doente, mesmo que esta possa provocar a sua morte: "o médico que, respeitando a vontade do paciente, não intervém e não o salva, não comete a infracção $[\mathrm{sic}]^{\prime 24}$.

Pode-se notar que a diferença primordial entre a ortotanásia e o auxílio ao suicídio, neste caso, está na omissão do médico, naquela, ou na ação realizada pelo profissional, neste. Não se pode dizer que a omissão é menos grave do que a ação, visto que ambas levarão, na questão em tela, ao mesmo resultado concreto: a morte, que é o objeto da pretensão do doente. Portanto, há de se colocar, paralelamente ao caso em que, quando da recusa de tratamento por parte do paciente, não há a punição do médico responsável - que não intervém a seu pedido e, por consequência, não o salva - a questão do profissional que, diante da súplica do doente, não se omite, porém age de modo a ajudá-lo a colocar fim à sua vida. Se na realização de ambos os procedimentos o resultado morte - é o mesmo, poder-se-ia abarcar o consentimento do ofendido no caso em que terceiro auxilia o enfermo a dar fim à própria vida, tendo em vista que a ajuda ao suicídio traz, na prática, maior dignidade em fim de vida do que a ortotanásia, já que a omissão médica - ao não dar prosseguimento no tratamento - apesar de "não interferir no tempo da morte"22, é muito mais dolorosa e traz maior tormento ao paciente do que a interrupção antecipada da vida, procedimento rápido e indolor.

Finalmente, como bem elucida Roxin (apud
Figueiredo Dias, 2012) 24, "uma vez que a participação no suicídio não é punível, só pode fundar-se a autoria por homicídio quando se puder negar a responsabilidade do suicida pelo seu acto [sic]". Logo, conforme teoriza o autor, a pessoa a dar o auxílio só será culpável se o doente não tiver responsabilidade alguma sobre o ato que o leva à morte.

Dessa maneira, a simples ajuda ao suicídio não seria punível, ocorrendo, entretanto, a punibilidade do agente nos casos em que o médico ultrapassa o auxílio e acaba por matar, sozinho, o paciente, cometendo um homicídio, ou quando ajuda o enfermo que não tem capacidade para realizar o pedido de assistência ao suicídio. Além do mais, descarta-se a possibilidade de autoria mediata - quando o autor domina a vontade alheia - já que esta "pressupõe sempre a comprovada falta de decisão autónoma [sic] e autorresponsável do 'suicida"' 24 . Faria Costa (apud Raimundo, 2014) ${ }^{3}$, em conclusão, vai mais longe, ao apontar que nem mesmo a eutanásia, quando realizada por profissional enquanto cumpridor de ato de curar para além da cura, no sentido de minorar sofrimento, não deveria preencher a tipificação de crime, uma vez que se trata de um ato médico, conforme o artigo $150^{\circ}$ do diploma penal, não sendo considerado um ataque à integridade física nem à vida.

\section{O AUXÍLIO AO SUICÍDIO NO MUNDO}

A ajuda à morte é motivo de controvérsia mundial, pois lida com a vida humana, bem jurídico cuja tutela constitui dever dos Estados. Consequentemente, vários países ainda criminalizam esta prática. Entretanto, inúmeras nações têm permitido sua realização, baseadas no princípio da morte digna, o qual prevê que as pessoas têm direito de ver sua dignidade respeitada, não apenas em todos os momentos da vida, mas também quando se encontram no caminho para a morte.

\section{Alguns países onde o suicídio assistido é permitido}

Segundo dados da organização EuthanasiaFree $N Z^{25}$, há quatro lugares no mundo que aceitam a prática da eutanásia juntamente com o suicídio assistido: Holanda, Luxemburgo, Canadá e, mais recentemente, o estado de Victória, na Austrália. Além disso, na Bélgica e Colômbia, apenas a eutanásia é legalizada, enquanto apenas o suicídio assistido é permitido na Suíça, Alemanha e em sete jurisdições dos Estados Unidos.

A Suíça é mundialmente conhecida pela institucionalização do auxílio ao suicídio, que ocorre através de organizações voluntárias, sem fins lucrativos. Uma das mais famosas é a Dignitas, que se dedica a dar a assistência não somente a nacionais, como também a estrangeiros que viajam até lá com a finalidade única do suicídio. Em maio de 2018, foi realizada uma emenda 
- através da Lei $\mathrm{n}^{\mathrm{o}} 11870 / 2018$ - na loi sur la sanité ${ }^{26}$, que regula o auxílio ao suicídio no cantão de Genebra. A legislação passou a garantir o direito ao auxílio ao suicídio nos estabelecimentos médico-sociais (EMS) e hospitais.

Conforme a nova redação da lei, estes estabelecimentos, públicos ou privados, não poderão recusar ajuda ao suicídio, contanto que o paciente tenha capacidade de discernimento ao realizar o pedido, persista em sua decisão, sofra de doença ou sequela de acidente grave e incurável, e lhe tenham sido apresentadas pelo médico todas as alternativas e os cuidados paliativos possíveis. De resto, em caso de dúvida sobre essas condições, o médico poderá submeter o caso à análise de uma comissão que, formada por um médico, um representante da Direção-Geral da Saúde, um especialista em bioética, um advogado e um representante de organizações de defesa dos pacientes, terá o poder de levar a questão ao promotor público ${ }^{26}$. Legislações similares já existiam nos cantões de Vaud e Neuchâtel ${ }^{27}$.

Nessa linha, o documentário The Suicide Tourist ${ }^{28}$ tem como palco a Suíça e mostra a realização do procedimento pela Dignitas. Aborda, de maneira interessante, a questão do turismo suicida, denominação dada ao ato de ir a outro Estado para fazer cumprir a vontade de ter auxílio à morte. Apesar da denominação liberal, deve-se esclarecer que, no País, malgrado o auxílio ao suicídio ser mais facilmente realizado do que em outros lugares, visto que são aceitos pacientes saudáveis e pessoas estrangeiras, o procedimento deve seguir requisitos essenciais estipulados em lei e não pode, de modo algum, ser arbitrário.

Já nos Estados Unidos, a lei federal proíbe apenas a eutanásia ativa. Como bem citado em relatório elaborado pelo Conselho Nacional de Ética para as Ciências da $V_{i d a}{ }^{29}$, o suicídio assistido é regulado no País pelas leis estaduais, sendo que algumas províncias permitem o procedimento. Dentre elas, pode-se citar Colorado, Oregon, Vermont, Washington (além do Distrito Federal), Califórnia, Montana e mais recentemente o Havaí. Para além da prerrogativa dada a cada Estado para decidir sobre a proibição ou não da assistência ao suicídio, cada Unidade Federativa tem ainda a autonomia de criar requisitos para a regulação do procedimento. Conforme André Dias Pereira ${ }^{30}$, na província da Califórnia, a lei End of Life Option Act permite que os médicos prescrevam drogas letais, mediante cumprimento de vários requisitos, a serem administradas pelo próprio doente, a seu tempo.

No Canadá, por sua vez, como bem assinalam Pinto e Cunha ${ }^{21}$, a Suprema Corte julgou, em 2015, inconstitucional a proibição do auxílio ao suicídio, na decisão do caso número 35591, conhecida como Carter v. Canada. No julgado, passou a ser considerado que a morte assistida constitui continuação do tratamento da doença terminal. Foi sustentado, ainda, que sua proibição criaria um dever de viver ao invés de um direito à vida.

$\mathrm{Na}$ Holanda, o auxílio ao suicídio é regulado juntamente com a eutanásia, sendo ambos os procedimentos permitidos. A lei que os regulamenta fez adaptações ao Código Penal para que tais atos não fossem mais criminalmente sancionados ${ }^{21}$. Na Finlândia, embora a eutanásia seja considerada crime de homicídio privilegiado, o suicídio assistido não é punível, apesar de violar o código de ética dos médicos ${ }^{21}$. Já na Suécia, "se o auxílio vier de pessoa que não exerça uma função médica, não há punição, mas, se advier de médico ou outro profissional de saúde, as normas éticas da profissão podem mostrar-se violadas", conforme assinalam Nunes, et al. ${ }^{31}$

Por fim, na Alemanha, o auxílio ao suicídio não é criminalmente punido. Entretanto, se o enfermo perder a consciência no momento da realização do procedimento e as pessoas que com ele estejam não tentarem evitar sua morte, estas podem ser enquadradas no crime de falta de assistência à pessoa em perigo. $\mathrm{Na}$ Colômbia, por outro lado, apesar de a prática da ajuda ao suicídio ser punida criminalmente, quando destinada a findar intensos sofrimentos resultantes de doença grave e incurável, há redução da pena ${ }^{21}$.

\section{O CAMINHO PARA A DESPENALIZAÇÃO DA AJUDA AO SUICÍDIO}

Primeiramente, consoante exposto, entendese pela necessidade do estabelecimento de requisitos básicos para que se caminhe para a despenalização e possível legalização do procedimento, pois acreditase que, quanto mais se especificar os casos permitidos, com mais facilidade sua aceitação ocorrerá. Há de se colocar em evidência, portanto, as exigências que se consideram essenciais para que o suicídio assistido seja realizado: a presença de um médico responsável pela prescrição e/ou administração do medicamento. Além disso, o paciente deve ter sido diagnosticado com doença incurável ou condição de saúde irreversível, cuja situação seja terminal. Deve também o pedido ser feito pelo próprio enfermo, que necessitará ter consciência plena e capacidade mental suficiente para realizá-lo.

Destarte, importante salientar parecer ${ }^{29}$ do Conselho Nacional para as Ciências da Vida (CNECV) sobre a proposta legislativa portuguesa $n^{\circ} 418 / \mathrm{XII} / 2^{\mathrm{a}}$, que regulava o acesso à morte medicamente assistida. O documento aponta que o projeto de lei atribuía ao profissional médico a última palavra no pedido de ajuda ao suicídio, uma vez que sugeria submeter a súplica a sucessivos pareceres médicos, com o fim de validar a concordância das opiniões dos profissionais e também a consistência do pedido. Estes requisitos elevariam a burocracia do procedimento, o que, diante da recorrência 
de perguntas ao adoentado e, pela evidente insuficiência da sua simples vontade, restaria sofrimento adicional para ele e a atribuição, ao médico, da última palavra, fazendo com que sua autonomia ficasse comprometida.

Ademais, mencionado parecer concluiu que, uma vez que o projeto legislativo pressupunha a interferência central do médico na prescrição dos meios para que o enfermo realizasse a morte e que, contrariamente, o código de conduta profissional dos médicos não permitiria a sua intervenção nessas práticas, teoricamente a questão pela qual o projeto girava em torno não se limitaria à procura de um médico que realizasse o procedimento, mas necessitaria também assegurar que a prática regular do suicídio assistido fosse incluída nas obrigações dos profissionais médicos, sem violar princípios e deveres relativos à sua função.

Outrossim, deve-se perceber a busca pela ajuda ao suicídio como a última opção do paciente, precisando este ter já recebido toda espécie de cuidados paliativos disponíveis, além de informações e esclarecimentos sobre sua situação de saúde e suas opções em fim de vida. Como bem enuncia o parecer, é correto que o Estado primeiramente procure combater a desigualdade no âmbito da saúde em vida, criando condições para um acesso efetivo de toda a população aos cuidados - para que possa viver com o máximo de qualidade possível até a morte - para então, posteriormente, regular e legislar a respeito dos pedidos de morte ${ }^{29}$.

Dessa maneira, o caminho para a despenalização do auxílio ao suicídio adviria primeiramente da aceitação, pelo Estado, da existência do princípio da morte com dignidade e de sua implicação: o fato de que a dignidade humana deve ser respeitada ao final da vida. A partir disso, urge-se àquele criar políticas públicas em atenção ao cuidado de pessoas em fim de vida, para somente então legislar sobre o procedimento em questão.

Partindo desse pressuposto, não se entenderia o auxílio ao suicídio como um homicídio, mas sim como a ajuda para pôr fim a um sofrimento visto pelo doente como desnecessário. Consequentemente, a continuação da vida seria tão somente uma prolongação das dores do enfermo, que caso preferisse, poderia receber o auxílio necessário para pôr fim à vida no lugar de esperar, em meio a intenso sofrimento, a chegada de uma morte certa e iminente.

\section{Viabilidade e questões bioéticas}

Há viabilidade na realização do procedimento, uma vez que é um processo já praticado em alguns países e que exige basicamente a técnica médica e a prescrição da droga a ser utilizada, visto que, em regra, o paciente já se encontra internado em instalações hospitalares.

Um dos questionamentos bioéticos está na manipulação de vidas pela medicina e tecnologia. Alguns consideram que o auxílio ao suicídio se trata de espécie de adulteração do ciclo da vida, uma vez que induz a morte. Entretanto, conforme já apresentado, entende-se que pela realização da ajuda ao suicídio não se manipula a vida, apenas se antecipa o inevitável, tendo em vista o estado terminal do paciente.

Com relação a esse tema, e contrariamente à modificação do ciclo normal da vida, a ortotanásia é um procedimento comumente permitido ao redor do globo, inclusive em Portugal, e que objetiva trazer a morte natural ao doente. Entende-se que a morte assistida poderia ser uma alternativa à ortotanásia, tendo em vista que esse procedimento agrediria mais a dignidade humana em fim de vida, já que muitas vezes, ao desligar os aparelhos que manipulam a duração da vida, o paciente passa a sofrer ainda mais e, em alguns casos, pode demorar a morrer. Estar-se-ia, então, infligindo dores a uma pessoa que intenciona apenas que sua vida termine, enquanto se poderia, com a simples ajuda de um ato médico, pôr fim a essa agonia de modo indolor. Posto que em ambos os casos o resultado é a morte, a realização do suicídio assistido no lugar da ortotanásia daria à pessoa uma morte com mais dignidade, terminando seu sofrimento de maneira mais rápida.

\section{Autonomia da vontade, objeção de consciência e autodeterminação}

A autonomia da vontade traduz-se na liberdade que todo indivíduo tem de realizar atos de acordo com seu próprio arbítrio. No campo da saúde, como elucida Baptista $^{32}$, até o século XX, o respeito pelo doente nem sempre incluía o respeito pela sua liberdade. O médico realizava o que entendia ser o certo para o paciente, protegendo sua saúde biológica. Reinava o paternalismo médico. Conforme princípios de beneficência, o profissional, uma vez que detinha conhecimento médico, fazia o que considerava ser o melhor para a saúde do doente, desconsiderando, entretanto, a vontade da pessoa, uma vez que nem sempre o que o indivíduo buscava era estar medicamente melhor.

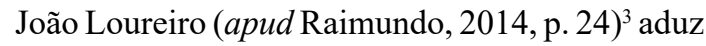
que a alteração do modelo compreensivo do ato médico constitui uma revolução paradigmática na medicina, uma vez que marca o fim do modelo paternalista, o qual se centrava no papel do médico, que interpretava a vontade - hipotética - do doente e decidia quais atos iria praticar, o que dava ao paciente um papel passivo. Como bem expõe Raimundo ${ }^{3}$, na atualidade o centro da questão é o doente. Mesmo que o ato médico em causa seja em seu proveito, cabe a ele exercer seu direito à autodeterminação curativa, dando seu consentimento para a prática dos atos que concernem à sua saúde.

Ainda segundo a autora, com a doutrina iluminista adveio o pensamento focalizado nos direitos humanos e 
nas liberdades fundamentais, e iniciou-se a considerar a liberdade e a autonomia dos indivíduos como princípios a serem seguidos: "atendendo à realidade sociológica, política e filosófica da época, os princípios de liberdade e autonomia individual começam então a ser reivindicados e a tornar-se relevantes na sociedade ${ }^{3}$ ".

A autonomia do paciente é uma questão que, hodiernamente, se coloca no debate bioético da permissão do auxílio ao suicídio, visto que ultrapassa a vontade médica e deixa ao doente o arbítrio de decidir sobre sua morte. Joel Feinberg (apud Baptista, 2012, p. 4) ) $^{32}$ declara que, através do conceito de autonomia e direito, a pessoa humana adquire seu sentido de identidade como ser moral e livre, merecedor de respeito. Seria essa liberdade, portanto, o direito dado a todo ser humano de exigir que os outros respeitem as decisões que toma e que são relativas a si.

No campo médico, mais especificamente quanto ao suicídio assistido, este autogoverno é reconhecido no momento em que o profissional da saúde suporta o pedido do enfermo. Importante salientar que o respeito pela opção do doente não traduz a aceitação do médico ao procedimento, uma vez que o profissional deve respeitar a autonomia do paciente e sua vontade de ter auxílio para morrer, mesmo que não fique vinculado a realizar o trâmite. Entende-se que quando não desejar prestar o auxílio à morte, o profissional da medicina tem a faculdade de invocar a objeção de consciência e encaminhar o paciente para outro profissional. Conforme preceitua o artigo $12^{\circ}$ do Regulamento de Deontologia Médica português ${ }^{33}$, o médico dispõe do direito de recusa à realização de ato da sua profissão quando esta prática conflita com sua consciência, ferindo seus princípios de ética, moral, religião, filosofia, ideologia ou humanitarismo.

Há de se considerar também, no que diz respeito à autonomia da vontade, o nível de capacidade e de autodeterminação que o indivíduo detém no momento em que realiza o pedido de ajuda ao suicídio. Uma vez que a autonomia se relaciona ao respeito da vontade do paciente em relação à sua própria vida, deve esta ânsia advir do enfermo e não do médico. Além disso, como já explorado, essa vontade deve ser livre e plena, advindo de alguém capaz.

Frequentemente, levanta-se a questão de que a morte assistida seria apenas um meio para a eugenia, ou seja, a eliminação das pessoas consideradas não mais úteis à sociedade. A eugenia deve ser absolutamente refutada, pois viola profundamente direitos humanos essenciais como a vida, a igualdade e a autodeterminação. Em consequência disso, entende-se essencial que a pessoa doente a se submeter ao auxílio ao suicídio tenha plena consciência e total capacidade para se autodeterminar no sentido de realizar o pedido de ajuda para findar sua vida.

A autodeterminação traduz-se na realização de atos de maneira consciente, e conforme a própria vontade. Defende-se que a intenção de pôr fim à vida deve advir do doente, e jamais do médico. E, mais que isso, o enfermo deve ser juridicamente capaz para decidir em relação ao fim de sua vida. Como elucida Faria Costa (apud Raimundo, 2014, p. 24) ${ }^{3}$, cabe ao indivíduo decidir quando há ou pode haver ato médico. Desse modo, o autor acrescenta ao conceito de ato médico a autodeterminação e o consentimento informado do doente.

\section{CONSIDERAÇÕES FINAIS}

A dignidade humana é um princípio basilar dos Estados Modernos de Direito e o seu respeito é essencial e serve de sustentação a todas essas jurisdições. O auxílio ao suicídio ocorre quando uma pessoa ajuda a outra a tirar a própria vida. Procura-se defender requisitos básicos a serem cumpridos para que o suicídio assistido aconteça com fulcro no princípio da morte com dignidade, em conformidade com a autonomia da vontade do doente.

O princípio da morte digna é fruto do direito à vida com dignidade. Este, unido ao direito à saúde, convola-se na prerrogativa que se dá ao doente de morrer, a partir do momento em que ele não mais detém saúde suficiente para continuar a viver por tempo indeterminado, e considera que antecipar o fim da sua vida seria a única maneira de fazê-lo ser digno, através de uma boa morte.

A morte com dignidade é a razão essencial da prática do auxílio ao suicídio. Defende-se a despenalização do suicídio assistido por se entender que o indivíduo - possuidor do direito à vida e à saúde - uma vez arrebatado por uma doença terminal - razão pela qual passa por enorme sofrimento físico e/ou psicológico tem os seus direitos à vida digna e à saúde transformados na prerrogativa, que advém da autonomia individual, de receber auxílio para realizar suicídio - com base no princípio da dignidade no momento da morte - caso entenda que sua situação de saúde presente lhe retira a dignidade, o que poderia ser suprido através de um fim de vida rápido e indolor.

Através da assistência ao suicídio, procurase realizar o desejo último do enfermo, que sem mais chances de cura, pretende unicamente ter a morte que entende como digna. Os requisitos obrigatórios para seu feitio são aqueles considerados essenciais para que o procedimento não seja arbitrário e a morte realmente ocorra sem violação da dignidade: a terminalidade da doença ou condição de saúde, a realização por um médico, a capacidade do paciente para fazer o pedido e a reiteração e seriedade deste.

Em Portugal, a descriminalização do auxílio ao suicídio ver-se-ia viável a partir do momento em que ocorresse com base no consentimento do adoentado e na já recorrente prática da ortotanásia, uma vez que o suicídio assistido seria um meio mais humano e menos doloroso 
de colocar fim à vida da pessoa doente que o requer. Desse modo, a ajuda ao suicídio apenas seria punível se desrespeitasse os requisitos impostos à sua prática.

O instituto é descriminalizado por poucas jurisdições do globo, uma vez que, ao tratar do fim da vida humana, engloba o debate de questões bioéticas que põem em causa o princípio da morte digna, tais como a manipulação do ciclo normal da vida, a prática com fins eugênicos, a falta de capacidade do doente e sua autonomia para decidir sobre um assunto de tamanha importância. Porém, pode-se perceber que os países que permitem o suicídio assistido conseguiram fazer com que a dignidade em fim de vida não fosse violada, a partir do momento em que estabeleceram leis e requisitos especiais de acordo com os costumes de cada local, regulando com seriedade o procedimento.

Logo, uma vez que o tema já foi com sucesso legislado em algumas nações, que passaram a realizar o procedimento de maneira séria e eficaz, de acordo com o princípio da morte digna e da autonomia do paciente, percebe-se que o caminho para a legalização do suicídio assistido em outros países, especificamente Portugal, já começou a ser traçado, dependendo da permissão para a realização do procedimento do debate com a população local e do estabelecimento de requisitos a serem seguidos com rigor, e que não diminuam o ser humano como pessoa possuidora de direitos essenciais que devem ser resguardados.

Sassi APZ. Assisted Suicide in Portugal: the transcendence of the right to health based on the principle of dignified death and individual autonomy. Saúde, Ética \& Justiça. 2020;25(2):34-46.

\begin{abstract}
Assisted suicide consists of a type of euthanasia lato sensu, in which a person assists another to commit suicide. The procedure does not aim to bring death but to spare the person from pains they consider unnecessary, since due to their medical condition, their death is imminent. The perception of assisted suicide as a means to a dignified end of life comes from the union of the rights to life and health, the autonomy of the individual and the principle of human dignity. The objective of this research, aside from defending the procedure's practice based on dignified death, is to expose the bioethical controversies surrounding the theme and to present the current situation of assisted suicide in Portugal. For this, we initially used the Penal, Constitutional and Legal Medicine Law teachings, in addition to legal websites. Later, in a more detailed investigation, books and scientific articles with related themes were used, as well as documentary research on comparative law, through which we noticed that countries such as Netherlands, Switzerland and Belgium allow the procedure, provided that the requirements specified in the legislation are followed. As a result, we concluded that the path towards non-punishment has already been taken by many countries, based on the fact that assisted death retains its importance in the defense of individual autonomy, that is, in the power of choice that the human being has regarding their own life. Its prohibition violates not only the autonomy but also the self-determination and freedom of expression that are inherent to the existence of the human person.
\end{abstract}

KEY WORDS: Forensic Medicine; Right to Health; Right to Die; Euthanasia; Suicide, Assisted; Personal Autonomy.

\title{
REFERÊNCIAS
}

1. Caldas JMP, Santos ZMSA. Sobre o direito universal da assistência à saúde [editorial]. Rev Rene [Internet]. 2017 [Acesso em 2018 ago. 31];18(4):428. Disponível em: http:// periodicos.ufc.br/rene/article/viewFile/20194/30773. DOI: http://dx.doi.org/10.15253/2175-6783.2017000400001

2. Brasil. Ministério da Saúde. Declaração Alma-Ata sobre Cuidados Primários [Internet]. Brasília; 2002 [Acesso em 2020 mai. 12]. Disponível em: https://bvsms.saude.gov.br/ bvs/publicacoes/declaracao_alma_ata.pdf

3. Raimundo AON. O direito a uma boa morte: a procura da justificação para a não punibilidade da eutanásia Activa Directa [dissertação] [Internet]. Coimbra: Universidade de Coimbra, Faculdade de Direito; 2014. [Acesso em 2019 abr. 29]. Disponível em: https://estudogeral.sib.uc.pt/ bitstream/10316/28496/1/O\%20direito\%20a\%20uma\%20 boa\% $\%$ morte.pdf

4. Portugal. Constituição da República Portuguesa [Internet].
Portugal; 1976. [Acesso em 2020 mai. 12]. Disponível em: https://www.parlamento.pt/Legislacao/Documents/ constpt2005.pdf

5. Ferreira Couto DS. A autodeterminação e a eutanásia: análise a partir das neurociências [dissertação][Internet]. Coimbra: Universidade de Coimbra, Faculdade de Direito; 2017. [Acesso em 2019 abr. 29]. Disponível em: https://estudogeral.sib.uc.pt/bitstream/10316/84148/1/ Disserta\%C3\%A7\%C3\%A3o.pdf

6. Corte Europeia de Direitos Humanos. Convenção Europeia dos Direitos do Homem [Internet]. Estrasburgo; 1950 [Acesso em 2020 mai. 12]. Disponível em: https://www. echr.coe.int/Documents/Convention_POR.pdf

7. Assembleia Geral da ONU. Declaração Universal dos Direitos Humanos. 217 (III) A. Paris; 1948 [Acesso em 2020 mai. 12]. Disponível em: https://www.ohchr.org/EN/ UDHR/Documents/UDHR Translations/eng.pdf 
Sassi APZ. Suicídio Assistido em Portugal: a transcendência do direito à saúde com base no princípio da morte digna.

8. Pithan LH. A dignidade humana como fundamento jurídico das "ordens de não-ressuscitação". $1^{\mathrm{a}} \mathrm{ed}$. Porto Alegre: Edipucrs; 2004.

9. Portugal. Decreto-Lei $\mathrm{n}^{\mathrm{o}} 47344$, de 25 de novembro de 1966. Código Civil Português. Atualizado até a Lei 59/99, de 30/06 [Internet]. Diário da República Portuguesa. 1966 nov. 22 [Acesso em 2020 mai. 12]. Disponível em: https://www.igac.gov.pt/documents/20178/358682/ $\mathrm{C} \% \mathrm{C} 3 \% \mathrm{~B} 3$ digo+Civil.pdf/

10. Rodrigues GC, coordenadora. Interdição e inabilitação [Internet]. $1^{\text {a }}$ ed. Lisboa: Centro de Estudos Judiciários; 2015. [Acesso em 2020 jun. 25]. Disponível em: http:// www.cej.mj.pt/cej/recursos/ebooks/civil/Interdicao inabilitacao.pdf

11. United Nations. Chapter IV: Human Rights. Convention on the Rights of Persons with Disabilities [Internet]. Nova Iorque; 2006. [Acesso em 2020 jun. 25]. Disponível em: https://reaties.un.org/Pages/ ViewDetails.aspx $? \mathrm{src}=$ TREATY\&mtdsg_no $=\mathrm{IV}$ $15 \&$ chapter $=4 \&$ clang $=$ en

12. Brasil. Presidência da República, Subchefia para Assuntos Jurídicos. Lei $n^{\circ}$ 13.146, de 6 de julho de 2015. Institui a Lei Brasileira da Inclusão da Pessoa com Deficiência (Estatuto da Pessoa com Deficiência) [Internet]. Brasília, DF; 2015 [Acesso em 2020 jun. 24]. Disponível em: http:// www.planalto.gov.br/ccivil_03/_ato2015-2018/2015/lei/ 113146.htm

13. Pereira JL, Matos ACH. Avanços e retrocessos ao sentido de capacidade legal: panorama prospectivo sobre decisões existenciais de pessoas com deficiência. Pensar: Revista de Ciências Jurídicas. 2018;23(3):1-13. DOI: http://dx.doi. org/10.5020/2317-2150.2018.7583

14. Tartuce F. Alterações do Código Civil pela Lei 13.146/2015: repercussões para o Direito da Família e confrontações com o Novo CPC. Primeira parte [Internet]. São Paulo; 2015 [Acesso em 2020 jun. 25]. Disponível em: https:// flaviotartuce.jusbrasil.com.br/noticias/213830256/ alteracoes-do-codigo-civil-pela-lei-13146-2015

15. Silva V. Eutanásia: Perspectivas jurídicas e sociais para o debate no Brasil [Internet]. Fortaleza; 2016 [Acesso em 2019 jan. 14]. Disponível em: https://vitalsilva.jusbrasil. com.br/artigos/382046081/eutanasia-perspectivasjuridicas-e-sociais-para-o-debate-no-brasil

16. Portugal. Decreto-Lei $n^{\circ} 48 / 95$. Código Penal Português [Internet]. Diário da República Portuguesa, nº 63/1995, Série I-A. 1995 mar. 15 [Acesso em 2020 mai. 13]. Disponível em: https://dre.pt/web/guest/legislacaoconsolidada/-/lc/107981223/201708230200/indice

17. Coutinho MRM. O consentimento informado dos menores nasintervençõesmédicas:umanovaperspectiva[dissertação] [Internet]. Coimbra: Universidade de Coimbra, Faculdade de Direito; 2016. [Acesso em 2020 jun. 20]. Disponível em: $\quad$ https://eg.uc.pt/bitstream/10316/34861/1/O\%20 Consentimento\%20Informado\%20dos\%20Menores\%20 nas\%20Intervencoes $\% 20$ Medicas $\% 20$ Uma $\% 20$ nova $\% 20$ perspetiva.pdf

18. Couto ILD. O problema da idade da imputabilidade penal [tese][Internet]. Porto: Universidade Católica
Portuguesa, Escola de Direito; 2012. [Acesso em 2020 jun. 26]. Disponível em: https://repositorio.ucp. $\mathrm{pt} /$ bitstream/10400.14/9682/1/TESE-\%20Isabel\%20 Lu\%C3\%ADs\%20do\%20Couto.pdf

19. Gutierrez LP. O que é o paciente terminal?. Rev Assoc Med Bras. 2001;47(2):92. DOI: https://doi.org/10.1590/S010442302001000200010

20. Sassi APZ. "Homicídio Piedoso" - O Direito a Uma Morte Digna: Análise da Legalidade da Eutanásia Frente à Junção do Direito à Vida com o Princípio Constitucional da Dignidade da Pessoa Humana. Revista de Iniciação Científica e Extensão da Faculdade de Direito de Franca [Internet]. 2019 [Acesso em 2020 mai. 13];4(1):5165. Disponível em: http://www.revista.direitofranca.br/ index.php/icfdf/article/view/883/pdf. DOI: https://doi. org/10.21207/2675-0104.2019.883

21. Pinto JM, Cunha TM. Eutanásia e suicídio assistido: legislação comparada [Internet]. Lisboa: Assembleia da República; 2016. [Acesso em 2019 jan. 3]. Disponível em: https://www.parlamento.pt/ArquivoDocumentacao/ Documents/Eutanasia_Suicidio_Assistido_1.pdf

22. Villas-Bôas ME. A ortotanásia e o direito penal brasileiro. Revista Bioética [Internet]. 2008 [Acesso em 2020 jun. 20];16(1):61-83. Disponível em: http://revistabioetica.cfm. org.br/index.php/revista_bioetica/article/view/56/59

23. Brito TQ, Mata PS, Neves JC, Morão H. Direito penal: parte especial: lições, estudos e casos. Coimbra: Coimbra Editora; 2007.

24. Figueiredo Dias J, organizador. Comentário conimbricense do código penal: parte especial, tomo I. $2^{\mathrm{a}}$ ed. Coimbra: Coimbra Editora; 2012.

25. Euthanasia-Free NZ Inc. Opposing Euthanasia and Assisted Suicide in New Zealand [Internet]. Nova Zelândia. [Acesso em 2019 jan. 5]. Disponível em: https://euthanasiadebate. org.nz/about-us/

26. Suíça. Lei $\mathrm{n}^{\circ} 800.1$, de 06 de fevereiro de 1965. Loi sur la sanité [Internet]. 1965, fev. 06. [Acesso em 2020 mai. 12]. Disponível em: http://rsn.ne.ch/DATA/program/books/ rsne $/ \mathrm{htm} / 8001 . \mathrm{htm}$

27. Belzer S. La nouvelle loi sur l'assistance au suicide est entrée en vigueur à Genève [Internet]. Genebra; 2018. [Acesso em 2018 nov. $1^{\circ}$ ]. Disponível em: https://www. rts.ch/info/regions/geneve/9744534-la-nouvelle-loi-sur-1assistance-au-suicide-est-entree-en-vigueur-a-geneve.html

28. Zaritsky J, diretor. The suicide tourist [season 28, episode 4]. In: Frontline [tv series]. Canada; 2007. 56 min. color.

29. Conselho Nacional de Ética para as Ciências da Vida. Parecer sobre o Projeto de Lei n. ${ }^{\circ}$ 418/xiii/2a "regula o acesso à morte medicamente assistida" [Internet]. Lisboa: CNECV; 2018. [Acesso em 2019 abr. 29]. Disponível em: https://www.cnecv.pt/pt/pareceres/parecer-n-o-101-cnecv2018-sobre-o-projeto-de-lei-n-o-418-xiii-2

30. Pereira AGD. Prefácio. In: Godinho AM. Eutanásia, ortotanásia e diretivas antecipadas de vontade: o sentido de viver e morrer com dignidade. $1^{\mathrm{a}}$ ed. Portugal: Juruá Editora; 2016. p. 7-15.

31. Nunes L, Madeira LD, Horta e Silva S, relatores. Projecto 
Sassi APZ. Suicídio Assistido em Portugal: a transcendência do direito à saúde com base no princípio da morte digna.

de Lei n. ${ }^{\circ} 418 / \mathrm{XIII} / 2^{\mathrm{a}}$ intitulado "Regula o acesso à morte medicamente assistida": relatório [Internet]. Lisboa: Conselho Nacional de Ética para as Ciências da Vida; 2018. [Acesso em 2019 jan. 4]. Disponível em: https://www. cnecv.pt/pt/pareceres/relatorio8?download_document $=323$ 2\&token=a38beddf4fc36736717498d809c84901

32. Baptista BMMM. Autonomia do Doente: dos Fundamentos Teóricos às Diretivas Antecipadas de Vontade [dissertação] [Internet]. Covilhã: Universidade Beira
Interior; 2012. [Acesso em 2019 jan. 12]. Disponível em: https://ubibliorum.ubi.pt/bitstream/10400.6/1179/1/ Disserta\%C3\%A7\%C3\%A30\%20B\%C3\%A1rbara\%20 Baptista.pdf

33. Portugal. Ordem dos Médicos. Regulamento de Deontologia Médica, n ${ }^{\circ}$ 707/2016. Diário da República $\mathrm{n}^{0}$ 139/2016, Série II de 2016-07-21. P. 1-14. [Acesso em 2020 mai. 13]. Disponível em: https://dre.pt/application/ conteudo/75007439

Recebido em: 13/05/2020

Aprovado em: 05/09/2020 